\title{
Seroprevalence and Genotypic Analysis of Ehrlichia canis Infection in Dogs and Humans in Cauca, Colombia
}

\author{
Elkin Forero-Becerra, ${ }^{1 \star}$ Jignesh Patel, ${ }^{2}$ Heidy-C Martínez-Díaz, ${ }^{3}$ Paola Betancourt-Ruiz, ${ }^{3}$ Efraín Benavides ${ }^{4}$ Steven Durán, ${ }^{4}$ \\ Luz-A Olaya-Másmela, ${ }^{5}$ Eliana Bolaños, ${ }^{6}$ Marylin Hidalgo, ${ }^{3}$ and Jere W. McBride ${ }^{2}$ \\ ${ }^{1}$ Research Training Program, Fogarty International Center (Code 1 D43), University of Texas Medical Branch at Galveston, Galveston, Texas; \\ ${ }^{2}$ Department of Pathology, University of Texas Medical Branch at Galveston, Galveston, Texas; ${ }^{3}$ Grupo de Enfermedades Infecciosas, \\ Departamento de Microbiología, Facultad de Ciencias, Pontificia Universidad Javeriana, Bogotá D.C., Colombia; ${ }^{4}$ Grupo de Investigación \\ Epidemiología y Salud Pública, Facultad de Ciencias Agropecuarias, Universidad de La Salle, Bogotá, D.C., Colombia; ${ }^{5}$ Programa de Medicina, \\ Facultad de Ciencias de La Salud, Universidad Libre - Cali, Sede Valle del Lili, Santiago de Cali, Colombia; ${ }^{6}$ Secretaría de Salud del Departamento \\ del Cauca, Popayán, Colombia
}

Abstract. Ehrlichia canis infections have been reported in humans in Venezuela and Costa Rica. In this study, 506 healthy residents and 114 dogs from four municipalities (Cauca, Colombia) were surveyed and blood samples collected. Antibodies to $E$. canis in human and canine sera were evaluated using the Tandem repeat protein 19 (TRP19) peptide ELISA and indirect immunofluorescence assay (IFA). Ehrlichia canis TRP19 antibodies were detected in only 1/506 human sera, but the single positive sample was negative by IFA. The majority $(75 / 114 ; 66 \%)$ of dogs surveyed had antibodies to the $E$. canis TRP19 peptide by ELISA, and eight randomly selected sera were further confirmed by E. canis IFA. Genomic DNA samples obtained from 73 E. canis TRP19 ELISA-positive dog blood samples were examined by PCR targeting the $16 \mathrm{~S}$ ribosomal ribonucleic acid (rRNA) gene. Ehrlichia canis 16S rRNA was amplified in $30(41 \%)$ of the dogs, and 16 amplicons were selected for DNA sequencing, which confirmed that all were $E$. canis. A second PCR was performed on the 16 confirmed $E$. canis 16S rRNA PCR-positive samples to determine the TRP36 genotype by amplifying the trp36 gene. TRP36 PCR amplicon sequencing identified nine dogs infected with the U.S. E. canis TRP36 genotype (56\%), one dog with the Brazilian genotype (6\%), and six dogs with the Costa Rican genotype (38\%). Moreover, these molecular genotype signatures were consistent with serologic analysis using TRP36 genotype-specific peptides. Notably, there was no serologic evidence of $E$. canis infection in humans, suggesting that $E$. canis infection in dogs in Cauca is not associated with zoonotic human infection.

\section{INTRODUCTION}

Human infections with Ehrlichia species are increasingly being diagnosed in several countries, where factors such as the presence and number of reservoir animals and tick vectors in endemic areas could play a critical role in emerging infections. ${ }^{1}$ The genus Ehrlichia has six recognized species that infect humans or animals: Ehrlichia canis, Ehrlichia chaffeensis, Ehrlichia ewingii, Ehrlichia ruminantium, Ehrlichia muris, and Ehrlichia minasensis. ${ }^{2,3}$ Ehrlichia chaffeensis, E. ewingii, E. canis, and E. muris subsp. eauclairensis have been identified as causative agents of zoonotic emerging human infections, where the first three agents are also known to cause ehrlichiosis in dogs. ${ }^{4,5}$ Ehrlichia canis has been associated with human infections in Venezuela and Costa Rica by serological and molecular tests. ${ }^{6-8}$

Tandem repeat proteins (TRPs) in E. chaffeensis and $E$. canis are major immunoreactive proteins with species-specific linear epitopes in the tandem repeat domain. ${ }^{9}$ In particular, E. canis TRP19 and TRP140 are species-specific antigens with exposed, conserved surface domains, ${ }^{10-12}$ whereas the E. canis TRP36, is a species-specific antigen with different TR sequences among E. canis strains. ${ }^{13}$ Previous studies have demonstrated that TRP19 and TRP36 are excellent immunodiagnostic antigens. ${ }^{10,14,15}$ Tandem repeat protein 36 has been used in many studies to define genotypic differences among $E$. canis strains by sequencing the tandem repeat region which exhibits variability in the nucleic acid sequence and in the number of

*Address correspondence to Elkin Forero-Becerra, Grupo de Investigación en Medicina Veterinaria y Zootecnia (GIDIMEVETZ), Facultad de Ciencias Agropecuarias, Universidad Pedagógica y Tecnológica de Colombia, Av. Central del Norte No. 39-115, Tunja 150001, Colombia. E-mail: egforerob@unal.edu.co tandem repeats. ${ }^{6,16-18}$ Recently, differences in TRP36 epitope containing tandem repeats has been used to perform serogenotypic analysis and has revealed evidence of sequential or coinfections in dogs with multiple $E$. canis strains. ${ }^{16,18}$

In Colombia, several reports have established and documented the seroprevalence and/or molecular evidence of E. canis infection in dogs throughout the country. ${ }^{18-22}$ In addition, there are reports of human ehrlichiosis where cytoplasmic inclusions consistent with ehrlichial morulae have been visualized in peripheral blood smears of humans or Ehrlichia-reactive antibodies have been detected by indirect immunofluorescence assay (IFA). ${ }^{23,24}$

Using dogs as sentinels for human rickettsial diseases has been suggested as an approach for disease surveillance by One Health. ${ }^{25}$ In this study, we investigated the seroprevalence of $E$. canis infection in humans and dogs in municipalities of Cauca, Colombia, to investigate the prevalence of $E$. canis infection in dogs, characterize $E$. canis genotypes, and investigate the possible occurrence of zoonotic infections in humans who own infected dogs.

\section{MATERIALS AND METHODS}

Study population and sample collection. A crosssectional study was carried out in the Department of Cauca (Colombia, South America). Samples were collected between August and November of 2017 in four municipalities (see Supplemental Table S1). Those municipalities were selected according to previous reports of human tick infestations or tick bites, ecological conditions for development of tick populations, security warrant for the field collection personnel, and ease of access to the rural human populations. To establish an appropriate sample size for the human population, 
census data from each municipality mayor's office was accessed. A confidence level of $95 \%$ with a $5 \%$ margin of error and a $50 \%$ expected prevalence rate for rickettsial infection was used, providing a sample size of 385 people. A predefined epidemiological questionnaire was completed for each healthy adult volunteer to determine risk factors for rickettsial infection. Each dog owner provided information regarding the number of dogs owned, length of ownership, tick infestation, ticks present in the dwelling (presence and infestation duration), and type of treatment used to control ticks, if any.

Healthy human volunteers and their dogs were identified by using a house-to-house campaign. All volunteers signed an informed, explained consent before any information or blood samples were obtained. The research ethics board of the Basic Sciences College, Pontificia Universidad Javeriana, approved the informed consent (Meeting Minute Record No. 9: May 11, 2016). Whole blood and serum samples were collected by venipuncture from the median cubital vein in humans and cephalic vein in dogs. A total of 506 human (a sample size higher than initially calculated of 385 people) and 114 canine sera were collected for this study. All dogs were examined for ectoparasite infestation (ticks, fleas, and lice). The ticks were collected in $70 \%$ ethanol and transported to the Veterinary Parasitology Laboratory (Universidad de La Salle) for morphological identification using a stereoscope using standard taxonomic keys. ${ }^{26,27}$

ELISA. The ELISA to detect $E$. canis TRP19 antibodies has been described previously. ${ }^{16,18}$ In brief, 96-well microtiter plates (MaxiSorp, Nunc ${ }^{\circledR}$, \#50-112-3685, Invitrogen by Thermo Fisher Scientific) were coated overnight with TRP19 peptide $(1 \mu \mathrm{g} / \mathrm{well}$, $50 \mu \mathrm{L})$ and diluted in sterile phosphate-buffered saline (PBS). Dog and human sera were diluted (1:100) in blocking buffer (Trisbuffered saline with $0.1 \%, 20 \%$, and $10 \%$ horse serum) and added to the wells $(50 \mu \mathrm{L})$, and the plates were incubated at room temperature for 1 hour. The plates were washed, and reverse alkaline phosphatase (AP)-labeled secondary antibody conjugated with goat anti-human $\lg G(H+L)$ reverse AP-labeled antibody (Kirkegaard and Perry) or anti-dog lgG $(\mathrm{H}+\mathrm{L})$ reverse APlabeled antibody (50 $\mu \mathrm{L} ; 1: 5,000$; Kirkegaard and Perry Laboratories, Inc., Gaithersburg, MD.) were added and incubated at room temperature for 1 hour. After washing, $100 \mu \mathrm{L}$ of BluePhos substrate (Kirkegaard and Perry) was added, and the plates were incubated for 1 hour in the dark at room temperature. Color development after 30 minutes in the dark was determined at $A_{650}$ on a microplate reader (Versa Max, Molecular Devices, Sunnyvale,
CA) and analyzed with SoftMax ${ }^{\circledR}$ Pro 6 (version 6.5.1, Molecular Devices). The optical density (OD) value represents the value after subtraction of the negative control wells. ELISA OD values $>0.2$ were used as a threshold to identify positive samples. ${ }^{16}$ ELISA controls included a negative peptide and canine and human sera that were negative by TRP 19 ELISA and IFA to $E$. canis. Serum from a dog experimentally infected with $E$. canis (\#2995) was used as a positive control, whereas the negative control was serum from a healthy laboratory-reared $\operatorname{dog}^{28}$ Human monocytic ehrlichiosis patient serum was also used as a positive control and normal human serum as a negative control. Similar ELISA assay conditions were used for $E$. canis genotypespecific TRP36 linear peptides: U.S. genotype (TEDSVSAPA), Brazilian genotype (ASVVPEAE), and Costa Rican genotype (EASVVPAAEAPQPAQQTEDEFFSDGIEA). Cl of $95 \%$ was calculated for the results of serum samples from naturally infected dogs by WinEpi 2.0 software free-accessible online (Working in Epidemiology, The University of Zaragoza, Zaragoza, Spain, available at: http://www.winepi.net/) using an ELISA test sensitivity and specificity of $100 \%$ for the TRP19 peptide. ${ }^{14,29}$

Indirect immunofluorescence assay. Antigen slides were prepared from $E$. canis-infected $\mathrm{DH} 82$ cells, as described previously. ${ }^{28}$ Human and dog sera were diluted (1:100) in PBS, and $10 \mu \mathrm{L}$ was added to the antigen wells and incubated at $37^{\circ} \mathrm{C}$ for 30 minutes. The slides were washed with PBS, and $10 \mu \mathrm{L}$ of the Alexa Fluor ${ }^{\circledR} 488$ goat anti-human IgG or anti-dog lgG secondary antibody (1:100) (Invitrogen \#A-11013 by Thermo Fisher Scientific, Waltham, MA) was added to the slides and incubated for 30 minutes. After washing, slides were observed using an Olympus BX61 epifluorescence microscope (Tokyo, Japan).

PCR. Genomic DNA (gDNA) was extracted from whole blood from 73 dogs that had TRP19 antibodies by ELISA using the DNeasy Blood and Tissue Kit (250) (69,506, QIAGEN Group, Hilden, Germany). These samples were amplified by PCR for E. canis $16 \mathrm{~S}$ rRNA gene using primers ECA (5'-AACACATGCAAGTCGAACGGA-3') and HE3 (5' -TATAGGTACCGTCATTATCTTCCCTAT-3'), as previously described, ${ }^{30-32}$ using $2.5 \times 5$ Prime Hot Master Mix (Quantabio, QIAGEN, Beverly, MA). Ehrlichia canis Jake strain gDNA was used as a positive control and molecular grade sterile water as a negative control. Selected samples were sequenced to determined identity of the PCR amplicon. Amplified PCR products were visualized by agarose gel $(2 \%)$ electrophoresis containing $0.003 \%$ ethidium bromide carried out at $120 \mathrm{~V}$ for 40 minutes.

TABLE 1

Summary of blood, gDNA, and ticks obtained from dogs in Cauca municipalities

\begin{tabular}{|c|c|c|c|c|c|c|}
\hline \multirow[b]{2}{*}{ Municipality } & \multirow[b]{2}{*}{ Total dogs } & \multirow[b]{2}{*}{ Serum samples } & \multirow{2}{*}{$\begin{array}{l}\text { Genomic DNA } \\
\text { samples }\end{array}$} & \multicolumn{3}{|c|}{ Ticks from dogs ${ }^{\star}$} \\
\hline & & & & Amblyomma maculatum s.I. $\dagger$ & Amblyomma ovale & Rhipicephalus sanguineus s.I. \\
\hline \multicolumn{7}{|l|}{ La Sierra } \\
\hline $\begin{array}{l}\text { Juana Castaña } \\
\text { El Tambo }\end{array}$ & 4 & 4 & 2 & 2 & 0 & 4 \\
\hline El Zarzal & 16 & 16 & 9 & 0 & 0 & 43 \\
\hline El Placer & 18 & 18 & 9 & 0 & 2 & 68 \\
\hline Betania & 9 & 9 & 7 & 0 & 0 & 76 \\
\hline \multicolumn{7}{|c|}{ Santander de Quilichao } \\
\hline Lomitas Arriba & 17 & 17 & 12 & 0 & 0 & 150 \\
\hline Lomitas Abajo & 23 & 23 & 17 & 0 & 0 & 88 \\
\hline \multicolumn{7}{|l|}{ Caloto } \\
\hline Credo & 19 & 19 & 11 & 0 & 0 & 6 \\
\hline Huellas & 8 & 8 & 6 & 0 & 0 & 0 \\
\hline Total & 114 & 114 & 73 & 2 & 2 & 435 \\
\hline
\end{tabular}

† s.l. = sensu lato. 
TABLE 2

Serosurvey and PCR results from humans $(n=506)$ and dogs $(n=114)$ from four municipalities of Cauca (Colombia)

\begin{tabular}{|c|c|c|c|c|c|c|}
\hline \multirow[b]{2}{*}{ Municipality } & \multirow[b]{2}{*}{ TRP19 ELISA human samples } & \multirow[b]{2}{*}{ TRP19 ELISA dog samples } & \multirow[b]{2}{*}{ 16S rRNA gene dog samples } & \multicolumn{3}{|c|}{$\begin{array}{l}\text { Ehrlichia canis genotypes } \\
\text { trp36 gene }\end{array}$} \\
\hline & & & & US & $\mathrm{Br}$ & $\mathrm{CR}$ \\
\hline \multicolumn{7}{|l|}{ La Sierra } \\
\hline Juana Castaña & 0 & 4 & 1 & 0 & 0 & 0 \\
\hline \multicolumn{7}{|l|}{ El Tambo } \\
\hline El Zarzal & 0 & 9 & 2 & 2 & 0 & 0 \\
\hline El Placer & $1^{*}$ & 9 & 6 & 1 & 0 & 5 \\
\hline Betania & 0 & 7 & 3 & 2 & 1 & 0 \\
\hline \multicolumn{7}{|c|}{ Santander de Quilichao } \\
\hline Lomitas Arriba & 0 & 12 & 6 & 1 & 0 & 1 \\
\hline Lomitas Abajo & 0 & 17 & 6 & 0 & 0 & 0 \\
\hline \multicolumn{7}{|l|}{ Caloto } \\
\hline Credo & 0 & 11 & 4 & 1 & 0 & 0 \\
\hline Huellas & 0 & 6 & 2 & 2 & 0 & 0 \\
\hline Total & 1 & 75 & 30 & 9 & 1 & 6 \\
\hline
\end{tabular}

$\mathrm{Br}=$ Brazilian genotype (ASVVPEAE); CR = Costa Rican genotype (EASVVPAAEAPQPAQQTEDEFFSDGIEA); US = U.S. genotype (TEDSVSAPA).

* Sample was negative by indirect immunofluorescence assay.

Genomic DNA from selected 16S rRNA PCR-positive samples $(n=16)$ was amplified by PCR for $E$. canis trp36 DNA using the primers TRP36-F2 (5'-TTTAAAACAAAATTAACACACTA-3') and TRP36-R1 (5'-AAGATTAACTTAATACTCAATATTACT-3') for the external reaction, and TRP36-D-F (5'-CACACTAAAATGTATAATAAAGC-3') and TRP36-R1 for the hemi-nested reaction. ${ }^{6}$ The PCR amplification was performed as described earlier with some differences: $\left(95^{\circ} \mathrm{C}, 3\right.$ minutes), 30 cycles of denaturation $\left(95^{\circ} \mathrm{C}, 30\right.$ seconds), annealing $\left(45^{\circ} \mathrm{C}, 30\right.$ seconds), extension $\left(70^{\circ} \mathrm{C}, 1\right.$ minute $)$, and a final extension at $70^{\circ} \mathrm{C}$ for 5 minutes. The PCR amplification conditions were identical for the external and nested PCR reactions. PCR amplicons were purified using the MinElute ${ }^{\circledR}$ PCR purification kit (250) (28,006, QIAGEN). Then, they were sequenced at the Molecular Genomics Core of the University of Texas Medical Branch (Galveston, TX) using the Sanger method and analyzed by DNASTAR ${ }^{\circledR}$ Lasergene Genomics suite (version 14.1, DNASTAR Inc., Madison, WI) and SnapGene ${ }^{\circledR}$ Viewer (version 4.1.9, GSL Biotech LLC, Chicago, IL).

\section{RESULTS}

Humans and dogs in the study population. A total of 506 adults ( $>18$ years old) completed questionnaires and provided blood samples. A summary of the information of study participants is presented in Supplemental Table S2. Information obtained regarding the dogs and ticks included in this study is summarized in Table 1.

PCR. Genomic DNA samples $(n=73)$ were amplified by PCR targeting the $E$. canis $16 \mathrm{~S}$ rRNA gene. Amplicons were detected in $30(41 \%)$ samples by PCR. Selected samples $(n=16)$ were sequenced to identify the specific agent, and all samples had $100 \%$ homology to the $16 \mathrm{~S}$ rRNA gene sequence of the $E$. canis YZ-1 strain (GenBank accession No. CP025749.1). To determine the $E$. canis genotype of these 16 samples, we amplified the trp36 gene. We detected three different genotypes: United States $(n=9)$, Brazilian ( $n=1)$, and Costa Rican $(n=6)$ (Table 2). All three $E$. canis TRP36 genotypes were detected by PCR in the sequenced samples of the El Tambo municipality. The GenBank

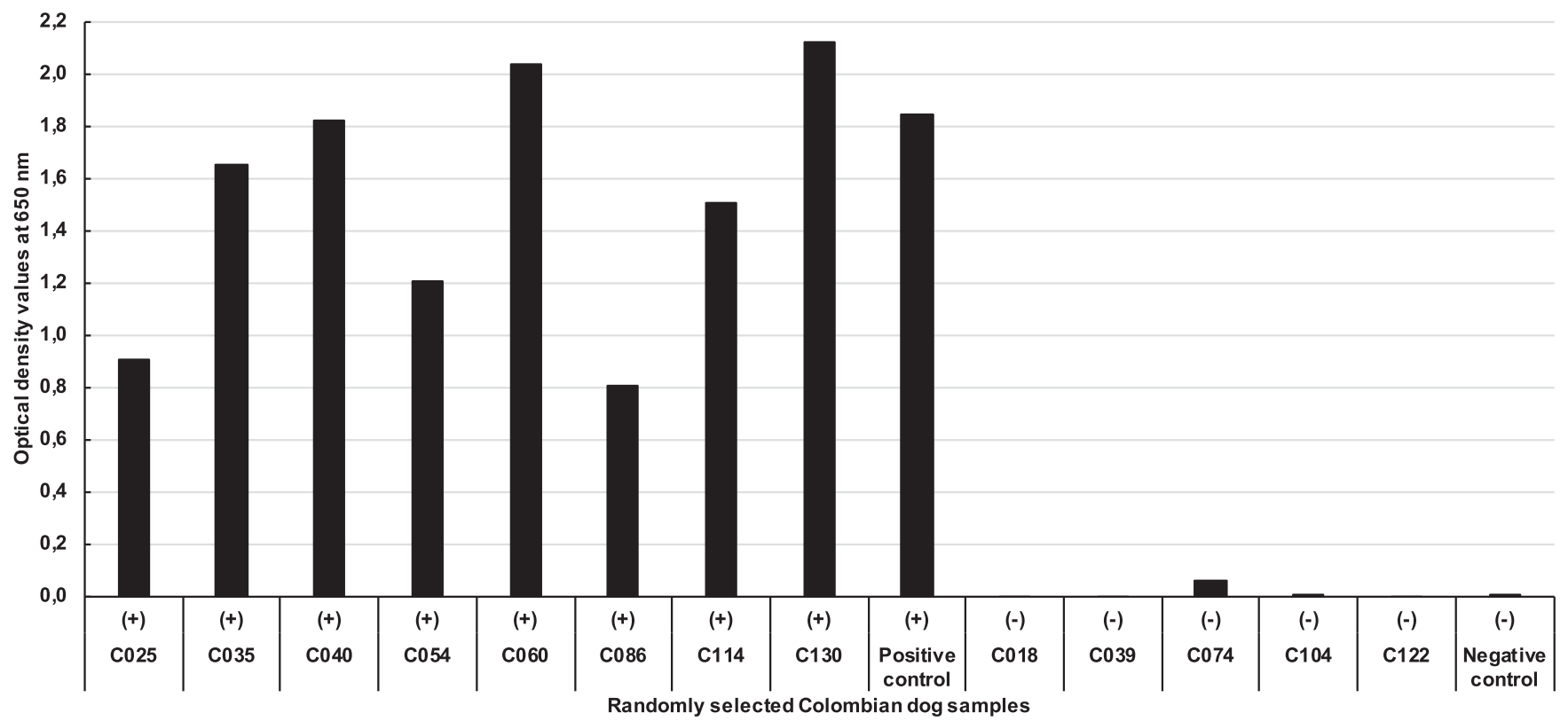

FIGURE 1. Immunoanalysis of 13 randomly selected Colombian dog sera showing correspondence between $E$. canis indirect immunofluorescence assay (IFA) and E. canis TRP19 ELISA (cutoff value, 0.2). E. canis = Ehrlichia canis. 
accession numbers for each of the 16 E. canis trp36 gene sequences are given in the Supplemental Table S3.

ELISA. Serosurvey results for the human and dog samples collected in four municipalities of Cauca are described in Table 2. All human samples were determined to be ELISA negative for anti-E. canis TRP19 peptide antibodies, except one sample (H181), which was negative by E. canis IFA. Over half $(75 / 114 ; 66 \%$; Cl: $57.1-74.5 \%)$ of the sera collected from dogs had detectable antibodies to the E. canis TRP19 peptide. Selected TRP19 ELISA-positive $(n=8)$ and -negative $(n=5)$ samples were tested by IFA to confirm $E$. canis antibody status (Figure 1). Subsequently, a serologic genotypic (United States, Brazil, and Costa Rica) investigation of 16 selected dogs was carried out in which TRP36 gene sequences were obtained by PCR. Most dogs (14/16; 88\%) had the highest antibody response to the TRP36 peptide that corresponded to the TRP36 genotype identified by TRP36 gene PCR/DNA sequencing (Figure 2). Half of these dogs $(n=8)$ had antibodies to more than one TRP36 peptide, suggesting sequential or coinfections had occurred. Data of Rhipicephalus sanguineus s.l. collection and E. canis serological or molecular detection did not follow a normal distribution (Supplemental Table S4). Also, no significant association of cross-tab data between these variables was found (Supplemental Table S5).

\section{DISCUSSION}

In this study, the proportion of E. canis 16S rRNA PCRpositive dog samples was similar to a previously reported study in Colombia, ${ }^{22}$ but higher than that in a report from Medellín (Colombia). ${ }^{18}$ Notably, other studies in Colombia have reported a lower prevalence of $E$. canis in dogs (between $15 \%$ and $28 \%$ ) using the $d s b$ gene by real-time PCR. ${ }^{20,21} \mathrm{We}$ unsuccessfully targeted the $E$. canis $d s b$ gene in the Colombian dog samples by conventional PCR, but a single-step E. canis $16 \mathrm{~S}$ rRNA gene PCR amplification provided increased sensitivity enabling detection of $E$. canis DNA. According to a meticulous review, ${ }^{30}$ PCR protocols targeting the 16S rRNA gene were developed for identification of genera within the Anaplasmataceae family, requiring subsequent PCR assays for identifying a species. Thus, we sequenced half of the

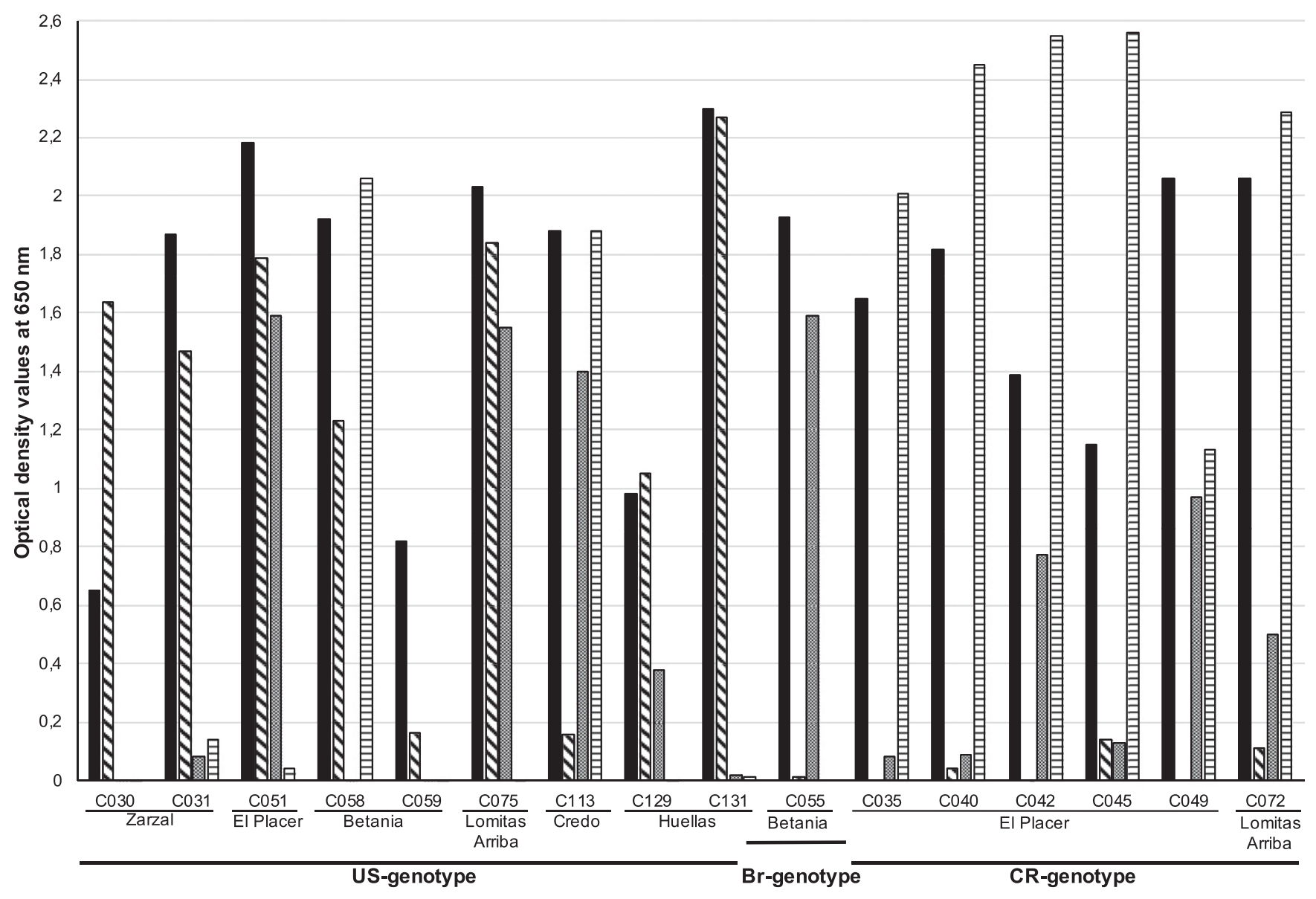

Colombian dog samples with E. canis genotype detection according to their rural district origin

-TRP19 peptide $\quad$ QUS-TRP36 peptide $\quad$ Br-TRP36 peptide $\quad$ CR-TRP36 peptides

FIGURE 2. Summary of 16 Ehrlichia canis trp36 PCR-positive and TRP36 genotype-specific peptides ELISA (cutoff value, 0.2). Br $=$ Brazilian genotype; $\mathrm{CR}=$ Costa Rican genotype; US = U.S. genotype. 
positive samples to confirm the identity of the amplicon. In addition, we targeted the $E$. canis trp36 gene for genotyping purposes and detected multiple $E$. canis genotypes, including the Costa Rican genotype, which has been detected in human blood bank donors in Costa Rica and in domestic dogs from Peru. ${ }^{6,17}$

As previously reported in Colombia, the high E. canis seroprevalence we detected in Cauca dogs is similar to that reported in other studies in Colombia, ranging from $62 \%$ to $82 \% .^{19,20,22}$ In those studies, dogs were from a mixed group of owned, military, shelter, and/or even free-roaming dogs presented at veterinary clinics for examination. Notably, a recent Colombian study found a seroprevalence of around $30 \%$ in 300 dogs attending veterinary teaching hospitals in Medellín. ${ }^{18}$ Although we observed a higher seroprevalence, this difference is likely to be explained by geographic (rural versus urban) differences in the selected dog population and tick density. ${ }^{33}$ In addition, the continuous and heavy exposure of dogs mainly to $R$. sanguineus sensu lato ticks in the endemic areas and a lack of adequate tick control programs may explain the high seroprevalence in these rural areas of Colombia. $^{34,35}$

The ELISA-based E. canis-specific TRP36 peptide seropositivity that we obtained is considered as evidence of active infection or previous exposure to $E$. canis. It is intriguing that the Colombian dogs infected with the Brazilian or Costa Rican genotypes showed no evidence of infection or exposure to the U.S. genotype. Also, none of the three $E$. canis genotypes were detected by ELISA at the same time in any sample. A previous research on 300 Colombian dogs from Medellin detected antibodies to the same three $E$. canis genotypes by ELISA in three dogs: one dog had the Costa Rican genotype and the remaining dogs had the U.S. genotype amplified by PCR. ${ }^{18}$ They found more dogs with the U.S. genotype, by serological and molecular tools, which is consistent with our results.

In our study, close contact of the surveyed individuals with tick-infested dogs was common. Such circumstance has been shown to increase the likelihood of finding ticks on humans in the U.S. east coast. ${ }^{36}$ However, in the large human serosurvey we conducted, only one human sample $(\mathrm{H} 181$, an elderly woman) was ELISA positive to the E. canis TRP19 peptide, but negative by the IFA test with the $E$. canis Jake strain antigen. Nevertheless, there was little evidence of E. canis transmission to humans in the individuals surveyed in our study. Although humans can be parasitized by $R$. sanguineus s.l. when cohabiting with tick-infested dogs, ${ }^{37}$ it is considered a rare event in countries such as Brazil where $R$. sanguineus is not frequently known to bite humans compared with other ixodid species in endemic areas. ${ }^{38}$

In conclusion, our serological findings regarding $E$. canis TRP36 genotypes suggest that sequential or coinfections with multiple $E$. canis genotypes may be occurring, as has been reported previously. ${ }^{16,18}$ The TRP36 genotype detected by ELISA, in most cases, elicited the predominant serological response to the peptide representing the respective genotype. Ehrlichia canis antibodies were not detected in human sera $(n=506)$, but a majority $(66 \% ; n=114)$ of dogs were seropositive. Three genotypes based on E. canis trp36 gene were detected in Cauca dogs representing the U.S., Brazilian, and Costa Rican genotypes. This study suggests that although $E$. canis infection in dogs is highly prevalent in these municipalities, there was no evidence of zoonotic transmission to humans. Moreover, considering the high seroprevalence, periodic epidemiological surveillance and effective control measures for the brown dog tick should be considered in these areas as a strategy to reduce $E$. canis infections in canines.

Received August 6, 2020. Accepted for publication January 12, 2021. Published online March 22, 2021.

Note: Supplemental tables appear at .www.ajtmh.org.

Acknowledgments: We express our gratitude to David Walker and Patricia Aguilar for their support during the Fogarty training process and providing guidance regarding Fogarty program objectives. In addition, Andrés Londoño Barbarán, a Fogarty postdoctoral fellow at the time, deserves a special recognition for his valuable advice about the use of serological and molecular tools for rickettsial research in Colombia. Finally, we appreciate all the technical support from Nicole Mendell and field collection personnel in Colombia.

Financial support: This work was supported by Colciencias (Project No. 120374455209, Colombia) and the Research Training Program of the Fogarty International Center (United States of America) (grant number 5D43TW010331-04).

Disclosure: U.S. patents for intellectual property related to the use of TRP19 and TRP36 for immunodiagnosis of $E$. canis infection have been awarded to J.W. M. An active license agreement to use TRP36 to diagnose $E$. canis infection exists between the inventors J. W. M. and the Research and Development Foundation and Antech Diagnostics.

Authors' addresses: Elkin Forero-Becerra, Grupo de Investigación en Medicina Veterinaria y Zootecnia (GIDIMEVETZ), Facultad de Ciencias Agropecuarias, Universidad Pedagógica y Tecnológica de Colombia, Boyacá, Colombia, E-mail: egforerob@unal.edu.co. Jignesh Patel, Department of Pathology, University of Texas Medical Branch at Galveston, Galveston, TX, E-mail: jgpatel@utmb.edu. Heidy-C Martínez-Díaz, Paola Betancourt-Ruiz, and Marylin Hidalgo, Grupo de Enfermedades Infecciosas, Departamento de Microbiología, Facultad de Ciencias, Pontificia Universidad Javeriana, Bogotá D.C., Colombia, E-mails: h-martinez@javeriana.edu.co, betancourtp@javeriana.edu.co, and hidalgo.m@javeriana.edu.co. Efraín Benavides and Steven Durán, Grupo de investigación Epidemiología y Salud Pública, Facultad de Ciencias Agropecuarias, Universidad de La Salle, Bogotá, D.C., Colombia, E-mails: efbenavides@unisalle.edu.co and sduran26@ unisalle.edu.co. Luz-A Olaya-Másmela, Programa de Medicina, Facultad de Ciencias de la Salud, Universidad Libre - Cali, Santiago de Cali, Colombia, E-mail: adrianaolaya26@gmail.com. Eliana Bolaños, Secretaría de Salud del Departamento del Cauca, Popayán, Colombia, E-mail: eliana.bolanos@cauca.gov.co. Jere W. McBride, Department of Pathology, Center for Biodefense and Emerging Infectious Diseases, Sealy Institute for Vaccine Sciences, University of Texas Medical Branch, Galveston, TX, E-mail: jemcbrid@utmb.edu.

\section{REFERENCES}

1. Ismail N, McBride JW, 2017. Tick-Borne emerging infections: ehrlichiosis and anaplasmosis. Clin Lab Med 37: 317-340.

2. Pritt BS et al., 2017. Proposal to reclassify Ehrlichia muris as Ehrlichia muris subsp. muris subsp. nov. and description of Ehrlichia muris subsp. eauclairensis subsp. nov., a newly recognized tick-borne pathogen of humans. Int J Syst Evol Microbiol 67: 2121-2126.

3. de Aguiar DM, Junior JPA, Nakazato L, Bard E, Aguilar-Bultet L, Vorimore F, Popov VL, Colodel EM, Cabezas-Cruz A, 2019. Isolation and characterization of a novel pathogenic strain of Ehrlichia minasensis. Microorganisms 7: 528.

4. Little SE, 2010. Ehrlichiosis and anaplasmosis in dogs and cats. Vet Clin North Am - Small Anim Pract 40: 1121-1140.

5. Allsopp MT, Louw M, Meyer EC, 2005. Ehrlichia ruminantium: an emerging human pathogen? Ann N Y Acad Sci 1063: 358-360.

6. Bouza-Mora L, Dolz G, Solórzano-Morales A, Romero-Zuñiga JJ, Salazar-Sánchez L, Labruna MB, Aguiar DM, 2017. Novel 
genotype of Ehrlichia canis detected in samples of human blood bank donors in Costa Rica. Ticks Tick Borne Dis 8: 36-40.

7. Perez $M$, Bodor $M$, Zhang $C$, Xiong Q, Rikihisa $Y, 2006$. Human infection with Ehrlichia canis accompanied by clinical signs in Venezuela. Ann N Y Acad Sci 1078: 110-117.

8. Perez M, Rikihisa Y, Wen B, 1996. Ehrlichia canis-like agent isolated from a man in Venezuela: antigenic and genetic characterization. J Clin Microbiol 34: 2133-2139.

9. Doyle CK, Nethery KA, Popov VL, McBride JW, 2006. Differentially expressed and secreted major immunoreactive protein orthologs of Ehrlichia canis and E. chaffeensis elicit early antibody responses to epitopes on glycosylated tandem repeats. Infect Immun 74: 711-720.

10. McBride JW, Doyle CK, Zhang X, Cardenas AM, Popov VL, Nethery KA, Woods ME, 2007. Identification of a glycosylated Ehrlichia canis 19-kilodalton major immunoreactive protein with a species-specific serine-rich glycopeptide epitope. Infect Immun 75: 74-82.

11. McBride JW, Corstvet RE, Gaunt SD, Boudreaux C, Guedry T, Walker DH, 2003. Kinetics of antibody response to Ehrlichia canis immunoreactive proteins. Infect Immun 71: 2516-2524.

12. Luo T, Zhang X, McBride JW, 2009. Major species-specific antibody epitopes of the Ehrlichia chaffeensis p120 and E. canis p140 orthologs in surface-exposed tandem repeat regions. Clin Vaccine Immunol 16: 982-990.

13. Aguiar DM et al., 2013. Genetic diversity of Ehrlichia canis in Brazil. Vet Microbiol 164: 315-321.

14. Cárdenas AM, Doyle CK, Zhang X, Nethery K, Corstvet RE, Walker DH, McBride JW, 2007. Enzyme-linked immunosorbent assay with conserved immunoreactive glycoproteins gp36 and gp19 has enhanced sensitivity and provides species-specific immunodiagnosis of Ehrlichia canis infection. Clin Vaccine Immunol 14: 123-128.

15. Zhang X, Luo T, Keysary A, Baneth G, Miyashiro S, Strenger C, Waner T, McBride JW, 2008. Genetic and antigenic diversities of major immunoreactive proteins in globally distributed Ehrlichia canis strains. Clin Vaccine Immunol 15: 1080-1088.

16. Aguiar DM, Zhang X, Braga IA, Taques IIGG, McBride JW, 2016. Detection of genotype-specific Ehrlichia canis exposure in Brazilian dogs by TRP36 peptide ELISA. Ticks Tick Borne Dis 7: 142-145.

17. Geiger J et al., 2018. Molecular characterization of tandem repeat protein 36 gene of ehrlichia canis detected in naturally infected dogs from Peru. Am J Trop Med Hyg 99: 297-302.

18. Arroyave E, Rodas-González JD, Zhang X, Labruna MB, González MS, Fernández-Silva JA, McBride JW, 2020. Ehrlichia canis TRP36 diversity in naturally infected-dogs from an urban area of Colombia. Ticks Tick Borne Dis 11: 101367.

19. McCown ME, Monterroso VH, Cardona W, 2014. Surveillance for Ehrlichia canis, Anaplasma phagocytophilum, Borrelia burgdorferi, and Dirofilaria immitis in dogs from three cities in Colombia. J Spec Oper Med 14: 86-90.

20. McCown ME, Alleman A, Sayler KA, Chandrashekar R, Thatcher B, Tyrrell P, Stillman B, Beall M, Barbet AF, 2014. Point prevalence survey for tick-borne pathogens in military working dogs, shelter animals, and pet populations in northern Colombia. J Spec Oper Med 14: 81-85.

21. Pesapane R, Foley J, Thomas R, Castro LR, 2019. Molecular detection and characterization of Anaplasma platys and Ehrlichia canis in dogs from northern Colombia. Vet Microbiol 233: 184-189.

22. Vargas-Hernández G, André MR, Faria JLM, Munhoz TD, Hernandez-Rodriguez M, Machado RZ, Tinucci-Costa M,
2012. Molecular and serological detection of Ehrlichia canis and Babesia vogeli in dogs in Colombia. Vet Parasitol 186: 254-260. 23. Montes-Farah J, De la Vega-del Risco F, Bello-Espinosa A, Fortich-Salvador AS, 2012. Co-infection of babesiosis and ehrlichiosis: a case in cartagena de Indias, Colombia. Rev CIENCIAS Biomédicas 3: 339-345.

24. Hidrón-Botero A, Muñoz-Ramirez F, Vega-Miranda J, 2014. First case of human monocytic ehrlichiosis reported in Colombia. Infectio 18: 162-166.

25. Bowser NH, Anderson NE, 2018. Dogs (Canis familiaris) as sentinels for human infectious disease and application to Canadian populations: a systematic review. Vet Sci 5: 83.

26. Jones EK, Clifford CM, Keirans JE, Kohls GM, 1972. The ticks of Venezuela (Acarina: Ixodoidea) with a key to the species of Amblyomma in the Western hemisphere. Brigham Young Univ Sci Bull 17: 11-18.

27. Nava S, Beati L, Labruna MB, Cáceres AG, Mangold AJ, Guglielmone AA, 2014. Reassessment of the taxonomic status of Amblyomma cajennense (Fabricius, 1787) with the description of three new species, Amblyomma tonelliae n. sp., Amblyomma interandinum n. sp. and Amblyomma patinoi n. sp., and reinstatement of Amblyomma mixtum Koch, 1844, and Amblyomma sculptum Berlese, 1888 (Ixodida: Ixodidae). Ticks Tick Borne Dis 5: 252-276.

28. McBride JW, Corstvet RE, Breitschwerdt EB, Walker DH, 2001. Immunodiagnosis of Ehrlichia canis infection with recombinant proteins. J Clin Microbiol 39: 315-322.

29. Ortega C, De Blas I, Simón MC, Gironés O, García J, Alonso JL, Muzquiz JL, Ruiz I, 2000. Information program applied to the temporal study of pathological processes in animal populations. Rev Sci Tech Off Int Des Epizooties 19: 735-743.

30. Guillemi EC, Tomassone L, Farber MD, 2015. Tick-borne Rickettsiales: molecular tools for the study of an emergent group of pathogens. J Microbiol Methods 119: 87-97.

31. Standaert SM, Dawson JE, Schaffner W, Childs JE, Biggie KL, Singleton J, Gerhardt RR, Knight ML, Hutcheson RH, 1995. Ehrlichiosis in a golf-oriented retirement community. $N$ Engl $J$ Med 333: 420-425.

32. Anderson BE et al., 1992. Detection of the etiologic agent of human ehrlichiosis by polymerase chain reaction. $J$ Clin Microbiol 30: $775-780$.

33. Gompper ME, 2014. The dog-human-wildlife interface: assessing the scope of the problem. Gompper ME, ed. Free-Ranging Dogs and Wildlife Conservation, 1st edition. Oxford, United Kingdom: Oxford University Press, 9-54.

34. Bowman D, Little SE, Lorentzen L, Shields J, Sullivan MP, Carlin EP, 2009. Prevalence and geographic distribution of Dirofilaria immitis, Borrelia burgdorferi, Ehrlichia canis, and Anaplasma phagocytophilum in dogs in the United States: results of a national clinic-based serologic survey. Vet Parasitol 160: 138-148.

35. Faccini-Martínez ÁA et al., 2017. Epidemiology of spotted fever group rickettsioses and acute undifferentiated Febrile Illness in Villeta, Colombia. Am J Trop Med Hyg 97: 782-788.

36. Jones EH, Hinckley AF, Hook SA, Meek JI, Backenson B, Kugeler $\mathrm{KJ}$, Feldman KA, 2018. Pet ownership increases human risk of encountering ticks. Zoonoses Public Health 65: 74-79.

37. Dantas-Torres F, Figueredo LA, Brandão-Filho SP, 2006. Rhipicephalus sanguineus (Acari: Ixodidae), the brown dog tick, parasitizing humans in Brazil. Rev Soc Bras Med Trop 39: 64-67.

38. Szabó MPJ, Pinter A, Labruna MB, 2013. Ecology, biology and distribution of spotted-fever tick vectors in Brazil. Front Cell Infect Microbiol 3: 27. 